\title{
IGREJA E UNIVERSIDADE: ESCOLA DE TEOLOGIA PARA LEIGOS E O PAPEL DA UNIVERSIDADE NO DESENVOLVIMENTO DO SABER HUMANO
}

\author{
CHURCH AND UNIVERSITY: SCHOOL OF THEOLOGY FOR THE LAITY AND \\ THE ROLE OF THE UNIVERSITY IN THE DEVELOPMENT OF HUMAN \\ KNOWLEDGE
}

\section{IGLESIA Y UNIVERSIDAD: ESCUELA DE TEOLOGÍA PARA LAICOS Y EL PAPEL DE LA UNIVERSIDAD EN EL DESARROLLO DEL CONOCIMIENTO HUMANO}

\section{ÉGLISE ET UNIVERSITÉ: ÉCOLE DE THÉOLOGIE POUR LES LAÏCS ET RÔLE DE L'UNIVERSITÉ DANS LE DÉVELOPPEMENT DES CONNAISSANCES HUMAINES}

\author{
Damião Conceição de Souza Borges ${ }^{1}$ \\ Moema Maria Badaro Cartibani Midlej ${ }^{2}$
}

\begin{abstract}
Resumo
A formação intelectual vem sendo uma exigência cada vez maior na sociedade contemporânea, em face da necessidade das pessoas em aprofundar conhecimentos. $O$ caráter formativo no interior da Igreja Católica estabeleceu-se no decorrer dos séculos, como instrumentos da cultura, para aprofundar seu constructo salvífico. Nesse sentido, a Igreja influenciou a criação de instituições escolares, eclesiais ou não, dentre as quais, a Universidade. Neste artigo, objetiva-se refletir sobre os entrelaçamentos na história entre as Instituições - Igreja e Universidade e a parceria entre a Escola de Teologia para Leigos - ETEL da Diocese de llhéus, Bahia e a Universidade do Estado da Bahia - UNEB. Nessa perspectiva, será discutida as influências exercidas pela Igreja na concepção da Universidade e as tensões entre o saber científico e a religião no desenvolvimento histórico das duas instituições, bem como as transformações ocorridas diante do imperativo de promover maior democratização no acesso ao conhecimento, formal ou não. De singular importância foi o Concílio Vaticano II, que promoveu mudanças na compreensão da Igreja, sobre a participação dos leigos na comunidade eclesial e o favorecimento à criação de escolas formativas para esse público. Foi nesse contexto que nasceu a ETEL, da Diocese de llhéus que, após 30 anos de atuação, firmou UNEB, para desenvolver projetos de curso propedêutico de Teologia para os leigos, no formato de extensão universitária, que vem sendo avaliado, positivamente, pelas instituições e pela sociedade.
\end{abstract}

Palavras-Chave: Igreja e Universidade; Teologia; Leigos; Saber humano.

\footnotetext{
1 Presbítero da Diocese de llhéus. Mestrando em Direito Canônico pelo Pontifício Instituto Superior de Direito Canônico do Rio de Janeiro, agregado à Pontifícia Universidade Gregoriana de Roma. Licenciado em Filosofia pela FBB, Bacharel pela UCSAL e chanceler da Cúria diocesana de llhéus. Contato: pe.damiaoborges@gmail.com

2 Doutora em Educação pela Universidade Federal da Bahia. Docente na Faculdade Madre Thais. Professora aposentada pela Universidade Estadual de Santa Cruz.

Contato: moema.midlej@gmail.com

ORCID: https://orcid.org/0000-0002-6621-2618
} 


\begin{abstract}
Intellectual training has been an increasing demand in contemporary society, given the need for people to deepen knowledge. The formative character within the Catholic Church has been established over the centuries, as instruments of culture, to deepen its salvific construct. In this sense, the Church influenced the creation of school institutions, ecclesial or not, among which, the University. In this article, we aim to reflect on the intertwining in history between the Institutions - Church and University and the partnership between the School of Theology for Dummies - ETEL of the Diocese of Ilhéus, Bahia and the State University of Bahia - UNEB. In this perspective, it will be discussed the influences exerted by the Church in the conception of the University and the tensions between scientific knowledge and religion in the historical development of the two institutions, as well as the transformations that took place before the imperative of promoting greater democratization in access to knowledge, formal or do not. Of singular importance was the Second Vatican Council, which promoted changes in the understanding of the Church, on the participation of the laity in the ecclesial community and favoring the creation of formative schools for this audience. It was in this context that ETEL was born, from the Diocese of Ilhéus, which, after 30 years of activity, signed UNEB, to develop projects of propaedeutic course of Theology for the laity, in the format of university extension, which has been positively evaluated by the institutions and by society.
\end{abstract}

Key words: Church and University; Theology; Lay people; Human knowledge.

\title{
Resumen
}

La formación intelectual ha sido una demanda creciente en la sociedad contemporánea, dada la necesidad de que las personas profundicen en el conocimiento. El carácter formativo dentro de la Iglesia Católica se ha ido consolidando a lo largo de los siglos, como instrumentos de cultura, para profundizar en su construcción salvífica. En este sentido, la Iglesia influyó en la creación de instituciones escolares, eclesiales o no, entre las que se encuentra la Universidad. En este artículo, nuestro objetivo es reflexionar sobre el entrelazamiento en la historia entre las Instituciones - Iglesia y Universidad y la asociación entre la Escuela de Teología para Laicos - ETEL de la Diócesis de Ilhéus, Bahía y la Universidad Estatal de Bahía - UNEB. En esta perspectiva, se discutirán las influencias que ejerció la Iglesia en la concepción de la Universidad y las tensiones entre conocimiento científico y religión en el desarrollo histórico de las dos instituciones, así como las transformaciones que se produjeron ante el imperativo de promover una mayor democratización en el acceso al conocimiento, formal o no haga. De singular importancia fue el Concilio Vaticano II, que promovió cambios en la comprensión de la Iglesia, sobre la participación de los laicos en la comunidad eclesial y favoreciendo la creación de escuelas formativas para esta audiencia. Fue en este contexto que nació ETEL, de la Diócesis de Ilhéus, que, tras 30 años de actividad, firmó la UNEB, para desarrollar proyectos de curso propedéutico de Teología para laicos, en el formato de extensión universitaria, que ha sido valorado positivamente por las instituciones y por la sociedad.

Palabras clave: Iglesia y Universidad; Teología; Laicos; Conocimiento humano.

\section{Résumé}

La formation intellectuelle est une demande croissante dans la société contemporaine, étant donné la nécessité pour les gens d'approfondir leurs connaissances. Le caractère formateur de l'Église catholique a été établi au cours des siècles, en tant qu'instruments de culture, pour approfondir sa construction salvifique. En ce sens, l'Église a influencé la création d'institutions scolaires, ecclésiales ou non, parmi lesquelles l'Université. Dans cet article, nous visons à réfléchir sur l'imbrication dans l'histoire entre les Institutions - Église et Université et le partenariat entre l'École de Théologie pour les Nuls - ETEL du Diocèse d'Ilhéus, Bahia et I'Université d'État de Bahia - UNEB. Dans cette perspective, il sera abordé les influences exercées par l'Église dans la conception de l'Université et les tensions 
entre savoir scientifique et religion dans le développement historique des deux institutions, ainsi que les transformations qui ont eu lieu avant l'impératif de promouvoir une plus grande démocratisation dans l'accès au savoir, formel ou ne pas. Le Concile Vatican II, qui a favorisé des changements dans la compréhension de l'Église, sur la participation des laïcs à la communauté ecclésiale et favorisant la création d'écoles formatrices pour ce public, a été d'une importance singulière. C'est dans ce contexte qu'est née ETEL, du diocèse d'Ilhéus, qui, après 30 ans d'activité, a signé l'UNEB, pour développer des projets de cours propédeutique de théologie pour les laïcs, au format d'extension universitaire, qui a été positivement évalué par les institutions et par la société.

Mots clés: Église et Université; Théologie; Laïcs; Connaissances humaines.

\section{Introdução}

A formação educacional que possa contemplar as diferentes classes de uma sociedade é algo exigente e requer, além de políticas públicas direcionadas para a educação formal, segundo conclusões da V Conferência Internacional de Educação de Adultos, realizada em julho de 1997, constantes na Declaração de Hamburgo, também, para "[...] a educação não formal e o espectro da aprendizagem informal e incidental disponível numa sociedade multicultural, onde os estudos baseados na teoria e na prática devem ser reconhecidos" (PAIVA; MACHADO; IRELAND, 2005, p. 38).

Nesse contexto, é necessário prioridade e desejo de enfrentar situações, que, por vezes, desafiam os que gerenciam o processo formativo, que objetive realmente alcançar todas as categorias, especialmente aquelas que menos têm acesso ao estudo sistemático. No entender de Severino (2006, p. 621);

\footnotetext{
Na cultura ocidental, a educação foi sempre vista como processo de formação humana. Essa formação significa a própria humanização do homem [...] $\mathrm{A}$ idéia de formação é, pois, aquela do alcance de um modo de ser, mediante um devir, modo de ser que se caracterizaria por uma qualidade existencial marcada por um máximo possível de emancipação, pela condição de sujeito autônomo. Uma situação de plena humanidade.
}

Formar pessoas é, pois, uma questão de prioridade, com viés pedagógico bem definido, acessibilizando os elementos conteudísticos a todos os que desejam progredir na reconfiguração do conhecimento, tendo em vista uma melhor visibilidade pessoal, trabalhista, social, religiosa e crescimento humano. 
Com este intuito, as Instituições educacionais buscaram, ao longo da história, diversas configurações formais e não formais, de atender esse anseio de conhecimento sistematizado, as quais vêm evoluindo ao longo do tempo histórico. Considera-se que as instituições mais longevas da humanidade, depois da Família, são a Igreja e a Escola (incluindo a concepção da Universidade), no seio das quais, a preocupação formativa, sempre esteve proeminente.

O caráter formativo no interior da Igreja Católica estabeleceu-se desde os seus primórdios, a partir da necessidade de evangelização, anúncio e educação da fé cristã. Assim, seu projeto educativo contou, no decorrer dos séculos, com instrumentos da cultura, para aprofundar seu constructo salvífico e, através dos documentos conciliares, estabeleceu uma relação entre a instituição e a sociedade ao longo do tempo, em face das transformações culturais, políticas e econômicas pela qual tem passado a humanidade.

No bojo da atuação da Igreja na história, com sólida formação do clero, reside a criação de instituições escolares eclesiais ou não, dentre as quais, de grande relevância, a concepção da Universidade, na Idade Média.

Atualmente, a lgreja, frente à necessidade de ampliar a participação dos fiéis na sociedade contemporânea e, tomando como direção os documentos produzidos no Concílio Vaticano II, o processo formativo vem tomando maior relevância com a criação de Escolas de Teologia para os leigos, especialmente à luz das constituições Lumen Gentium e Gaudium et Spes. inserindo-se na realidade expressa na declaração conciliar Gravissimum Educationis.

\section{Igreja e Universidade: entrelaçamentos na história}

Numa perspectiva histórica, as instituições humanas e sociais foram se estabelecendo em um processo civilizatório de respeito a regras e normas, atuando como mediadoras no processo de socialização do ser humano, e operando, de maneira formativa e educativa, nas culturas constituídas. Entre as instituições mais ancestrais do mundo, dividido em sociedades, depois da Família, estão a Igreja e a Escola, que dão à humanidade o arcabouço de civilidade, vivenciada ao longo do tempo. 
A Igreja é uma das instituições através das quais, populações de diferentes culturas, formularam códigos sociais e morais, e que, ao longo do tempo, estabeleceuse como "inconsciente coletivo na sociedade, enquanto a Escola tem a responsabilidade de introjetar nos indivíduos as normas sociais, legais e de comportamento, formando-os como cidadãos responsáveis e humanos.

Dentro de uma lógica histórica, a Igreja Católica, é a instituição pioneira na feitura de conhecimento acadêmico, sobretudo no mundo ocidental, através de uma de suas grandes invenções, a instituição de maior relevância para a educação de todos os tempos, a Universidade, como meio de expandir o conhecimento, como um verdadeiro instrumento para diminuir distâncias educacionais e sociais. Com base nessa "invenção" da Igreja Católica, que se deu em uma etapa da humanidade, conhecida como: Idade Média, mudou os conceitos e os jeitos de fazer educação no mundo. São João Paulo II, na Constituição Apostólica Ex Corde Ecclesiae, de 15 de Agosto de 1990, n. 1. Assim definiu a Universidade:

\footnotetext{
A Universidade é, nas suas origens, uma das expressões mais significativas da solicitude da Igreja. O seu nascimento está ligado ao desenvolvimento das escolas constituídas na Idade Média pelos bispos das grandes sés episcopais. Embora as transformações da história tenham conduzido a "Universitas magistrorum et scholarium" a tornar-se cada vez mais autónoma, nem por isso a lgreja deixa de por ela nutrir menos solicitude que na origem da sua instituição.
}

Assim, conforme assinala Midlej (2004), da origem das Universidades, localizadas na Europa no final do século XI - início do século XII, na Bolonha e Salermo (Itália) e Paris (França), até o Renascimento, criaram-se Instituições (studia generalia), dedicadas ao culto do saber e à discussão do conhecimento, que logo se multiplicaram no continente europeu, onde se praticavam, livremente, um aprendizado geral, ministrado por grupos de estudiosos e intelectuais a estudantes de toda cristandade, influenciados pela lgreja e atraídos pelo saber.

Foi essa influência religiosa que motivou reivindicações para implantação de um modelo corporativo (Universitas magistrorum et scholarium), que, mais tarde, passou a um formato denominado studium ou estabelecimento de Ensino Superior. Este modelo "tradicional", conhecido como "Universidade do Espírito" era voltado para um ambiente de educação. 
No Renascimento, o impacto das transformações ocorridas e os efeitos da rebeldia religiosa dos séculos XV a XVIII, a Universidade sofreu grandes alterações em sua concepção e organização. Neste contexto, a Universidade configurava-se como uma Instituição social aberta ao humanismo e às ciências. Assim, além do humanismo renascentista e dos movimentos religiosos e revolucionários, a nova relação entre a Universidade e a Ciência torna-se o elemento fundamental na nova estruturação da vida universitária.

Na modernidade, sob a influência do lluminismo e do Enciclopedismo do século XIX, a Universidade se estabeleceu sob o signo da razão, submetida às grandes transformações experimentadas pela humanidade, contribuindo para o avanço da ciência e tecnologia, para o progresso técnico e material.

A Universidade atual, conforme Boaventura de Sousa Santos (1999, p. 189) enfrenta os desafios impostos, precipuamente, quanto aos seus fins de ensino, investigação e prestação de serviços, que residem na exacerbação do conteúdo utilitarista e produtivista imputado à Instituição.

Nessa trajetória histórica, a Igreja Católica estava presente em todos os âmbitos sociais, culturais e políticos, exercendo grande poder, tanto no exercício da formação de indivíduos quanto na ordem política, econômica, social e cultural na evolução da humanidade, com reflexos significativos na instituição universitária.

De acordo com Laghi; Pironio e Poupard (2020, p. 3), "a Universidade abriu-se largamente a um vasto público, tanto no seu ensino inicial como na formação permanente. É um facto importante e significativo de democratização da vida social e cultural". Neste contexto, com o intuito de promover maior democratização no acesso da sociedade às suas atividades, a instituição universitária ampliou programas e projetos nas suas diversas funções (ensino, pesquisa e extensão), para permitir afluxo de pessoas de diferentes classes sociais e níveis de saberes. 


\section{Protagonismo do laicato}

Numa esfera interna da Igreja Católica, com o advento do Concílio Ecumênico Vaticano $\|^{3}$, realizado entre os anos 1962 a 1965, mudou, de maneira contundente, a compreensão da Igreja, destacando um envolvimento mais pujante de uma categoria conhecida como leigos ${ }^{4}$, que até esse momento da história da Igreja, tinha um papel irrelevante e anódino, ganhando um real e justo significado, sendo-Ihes esclarecido e defendido o seu verdadeiro lugar.

Com as novidades do dito Concílio, os leigos foram se colocando como protagonistas em sua participação na comunidade eclesial, não como algo facultado pela hierarquia, mas como um verdadeiro situar-se na dinâmica eclesial, tornando-se figuras de maior importância para a Igreja. "Cada cristão leigo e leiga é chamado a ser sujeito eclesial para atuar na Igreja e no mundo" (CNBB, Doc. 105, n. 1). Para isso, deve enraizar-se mais profundamente no ser e na missão da vocação laical, "reconhecendo o valor de seus trabalhos na Igreja e no mundo" (CNBB, Doc. 105, n. 10).

Na busca de encontrar seu espaço de agente dentro da Igreja Católica, os homens e mulheres, de todas as idades e classes sociais, iniciaram um processo de procura constante de "conquista" de seu espaço, a fim de que, como verdadeiros protagonistas, pudessem concorrer para um desenvolvimento dos elementos que são inerentes ao ser cristão.

$\mathrm{Na}$ esteira de um crescimento humano e da essência do ser cristão, diversas maneiras de disponibilizar materiais de aprofundamento da doutrina cristã e seus desdobramentos foram surgindo. Diferentes maneiras de disponibilizar conhecimentos doutrinais foram criadas, objetivando favorecer uma ascese na compreensão das questões elementares da prática de fé deles.

A Igreja Católica, especialmente na América Latina, de maneira muito recortada, no Brasil, muitas foram as salas e salões, bem como outros ambientes nos Templos católicos, foram sendo tomados pelos leigos e leigas, com o intuito de alargar

\footnotetext{
${ }^{3}$ Concílio é uma grande assembleia de Bispos da Igreja Católica, na qual toma lugar de proeminência o Papa, como seu presidente e que possui caráter deliberativo.

${ }_{4}$ A expressão leigo vem da expressão grega laós, que significa um dos membros do povo de Deus.
} 
horizontes, direcionar energias, potencializar os cristãos, colocar em prática as diretrizes do Concílio Ecumênico Vaticano II e diminuir, com o intuito de eliminar, a gritante separação entre hierarquia e laicato.

Neste contexto, de busca de conhecimento de questões ligadas à fé cristã, surgiram as chamadas Escolas de Fé e Política (CEFEP), como um jeito de favorecer aos demandantes uma formação humana, relacional, doutrinal, pastoral e social, tendo como ponto fulcral a diminuição, ou melhor, a eliminação do "analfabetismo" eclesial.

\begin{abstract}
Para cumprir sua missão com responsabilidade pessoal, os leigos necessitam de sólida formação doutrinal, pastoral, espiritual e adequado acompanhamento para darem testemunho de Cristo e dos valores do Reino no âmbito da vida social, econômica, política e cultural. [...] Isso exige, da parte dos pastores, maior abertura de mentalidade para que entendam e acolham o "ser" e o "fazer" do leigo na Igreja, que, por seu batismo e sua confirmação, é discípulo e missionário de Jesus Cristo. Em outras palavras, é necessário que o leigo seja levado em consideração com espírito de comunhão e participação (DAP, 2007, n. 212-213).
\end{abstract}

Desse desejo de favorecer aos cristãos leigos um maior conhecimento da fé, diferentes projetos surgiram de confecções de material gráfico, audiovisual e auditivo, que proliferaram Brasil afora, gerando uma busca impressionante dos leigos e leigas, que buscavam, avidamente, conhecer e aplicar as exigências do Evangelho de Jesus, o Deus humanizado 5 .

Desse movimento, que foi de grande eficácia para a Igreja Católica aqui no Brasil, surgiram muitas questões positivas, com destaque para as diferentes "rodas de conversas", cursos bíblicos, formações de agentes para as pastorais sociais, como a pastoral da criança, do menor, dos operários, do morador de rua, carcerária, esta, um pouco mais tarde, por volta de 1985.

Essa efervescência no envolvimento estudantil provocou uma busca constante, que foi desembocando uma estruturação dos organismos formativos. É nesse contexto que foram surgindo, as chamadas Escolas de Teologia para Leigos. Esse movimento estruturador de um estudo sistematizado, como uma maneira de

\footnotetext{
${ }^{5}$ Expressão denota a condição divina de Jesus, que não foi anulada, mas que assumiu, de maneira plena, a condição do ser humano, sem deixar de ser Deus, de acordo com São Paulo (cf. Fl 2, 6-11).
} 
unificação das já mencionadas Escolas da Fé e Política, não foi diferente na mais antiga diocese ou Igreja particular ${ }^{6}$ do Sul da Bahia, que é a de Ilhéus.

A escola surgiu com a finalidade de proporcionar "a formação dos leigos, agentes de pastoral nas diversas áreas da cidade de llhéus" e, também, para a formação de professores de Educação Religiosa nas escolas estaduais e municipais da cidade de llhéus. No Brasil, estava em andamento esse serviço para a formação cristã do laicato. Essa iniciativa é fruto da abertura que o Concílio Ecumênico Vaticano II (1962-1965) fez para toda a Igreja (MONTAGNOLI, 2020, p. 35).

As novidades surgidas com o Vaticano II contagiaram a Diocese de llhéus, que procurou corresponder os anseios do laicato, que eram sempre crescentes. Foi assim que o então Bispo diocesano, Dom Valfredo Bernardo Tepe, criou, em setembro de 1988, a Escola de Teologia para Leigos - ETEL, com dois objetivos muito claros: 1) oferecer uma formação mais qualificada e sistematizada para os leigos da região Sul da Bahia, na vasta área da Diocese de llhéus e, 2) qualificar professores da rede estadual e municipal de ensino, que lecionavam a disciplina de religião nas respectivas redes.

É exatamente neste pormenor, que as presentes linhas querem demarcar a intervenção das formas de estudo oferecido pela Igreja Católica, que, por conseguinte, geraram uma incidência direta na dimensão social das pessoas, que tiveram condições de crescer na esfera religiosa, anexada ao avanço acadêmico, financeiro e social.

A criação da ETEL da Diocese de Ilhéus se localiza neste contexto, inclusive, de pouca oferta de educação superior pelo Estado da Bahia. Por este prisma, vê-se, nitidamente, uma forma de intervenção social, através da educação, de uma organização de renome, que se propôs, no momento recortado (e continua cumprindo essa função formativa), que culminou na formação de uma gama de pessoas sem precedentes.

\footnotetext{
${ }^{6}$ Por Igreja particular compreende, a partir do Código de Direito Canônico, Cân. 368, que reflete o Concílio Vaticano II, as dioceses e demais instâncias que a elas são equiparadas.

${ }^{6}$ A expressão aqui inserida é para autenticar que está patenteado na constituição da Igreja católica o fator colaborativo e que ela não se nega a ajudar a humanidade, em quaisquer emergências que coloque a vida humana e a criação de modo geral em risco.
} 


\begin{abstract}
Da exigência de promover a identidade integral do homem nasce a proposta dos grandes valores que presidem uma convivência ordenada e fecunda: verdade, justiça, amor e liberdade. A pastoral social esforça-se para que a renovação da vida pública seja vinculada a um efetivo respeito dos sobreditos valores. De tal modo, a Igreja, mediante o seu multiforme testemunho evangélico, visa promover a consciência do bem de todos e de cada um como recurso inexaurível para o progresso de toda a vida social (DSI, n. 527).
\end{abstract}

No que diz respeito à nomenclatura, intervenção é um substantivo feminino, que caracteriza um ato de intervir, de exercer um tipo de influência em determinada situação, na tentativa de alterar o seu resultado; interferência. É, ainda, ação de expressar, escrita ou artisticamente, um ponto de vista, acrescentando argumentos ou ideias que sejam convincentes e sustentáveis.

Dentro de um viés de conhecimento, a Diocese de llhéus, por meio do seu organismo formativo, a Escola de Teologia para Leigos - ETEL, interveio, em momento singular da Igreja Católica, bem como na educação estadual e municipal, na cidade, em princípio, posteriormente, para as cidades do entorno, possibilitando o acesso ao curso de Teologia, em nível propedêutico, o que elevou o nível cultural, social, econômico e religioso de parcela significativa dessas populações.

A experiência da ETEL é uma maneira de acessibilidade e educação inclusiva, que tem por meta, a participação das pessoas, independente do seu nível cultural, social e religioso, haja vista que o objetivo maior era, e continua sendo, favorecer o avanço educacional/formativo dessas pessoas, das quais, muitas delas só tinham, como elemento de apoio, esse tipo de projeto.

Por esta perspectiva, é notório perceber uma maneira de educação integradora, altamente desburocratizada e acessível, visando um maior aproveitamento de conhecimento e de interatividade, e de incidência direta na esfera social.

$\mathrm{Na}$ atualidade, após 30 anos de existência da ETEL, com etapas peculiares e de reestruturação, esse organismo renovou-se estruturalmente, dando um passo significativo em sua caminhada educadora/formativa, abrindo novos horizontes e lançando-se para novas experiências, capazes de abarcar saberes diferentes e construir teia de laços, inclusive com instâncias educativas, na esfera estadual. 


\title{
4. Parceria ETEL e a Universidade do Estado da BAHIA - UNEB
}

No ano de 2018, com a assinatura de um convênio de cooperação com uma das mais significativas instituições de ensino superior do Estado, a Universidades do Estado da Bahia - UNEB, mediada por seu Centro de Estudos e Pesquisas Interdepartamental, Interinstitucional e Internacional em Culturas e Religiões CEPICR, configurando o curso de Teologia da Diocese de llhéus, como curso de extensão.

\begin{abstract}
Resumo do Acordo de Cooperação que entre si celebram a Universidade do Estado da Bahia e a Diocese de llhéus por meio da Escola de Teologia para Leigos (ETEL) OBJETO: Estabelecer a parceria e a Cooperação entre as partes com vistas a realizar a capacitação de cristãos leigos e pessoas da comunidade ingressas na Escola de Teologia para Leigos (ETEL) com a Cooperação do Departamento de Ciência Humanas e Tecnologia (DCHT) Campus 21, Ipiaú. VIGÊNCIA: 5 (cinco) anos, a partir da data de sua assinatura $(10 / 11 / 2018)(\mathrm{DO}, 2020)$.
\end{abstract}

Um marco de uma nova etapa para este organismo da Diocese de llhéus e adjacências, a parceria de cooperação entre a Diocese de llhéus e a UNEB demonstra o interesse de duas grandes instituições, que explicitam preocupação em potencializar pessoas de todas as classes sociais e de maneira oblativa.

Conforme sinalizam Alves e Assis (2020, p. 65), o projeto aprovado em ambas as instituições, vem tendo resultados exitosos,

[...] na medida em que têm contribuído em três frentes: na consecução da institucionalização acadêmica do curso de Teologia para Leigos, na formação dos cursistas de modo mais sistemático e na ampliação da participação da universidade junto à comunidade, na medida em que está diretamente envolvida no planejamento e execução de etapas da formação.

Essa nova categoria de curso, que para muitas pessoas em cidades que abrangem a Diocese de llhéus, é de grande significado, deu um grande impulso à Escola de Teologia, com agregação de muitos novos alunos, que a partir de então, terão oportunidade de aprofundar sobre os conteúdos da fé, da moral cristã, de filosofia, de doutrina social da Igreja e da história da Igreja, que coaduna com a história dessa nossa era. 


\section{Considerações finais}

Neste artigo, intencionamos dar ênfase ao entrelaçamento histórico entre as instituições Igreja e Universidade, experienciado em determinados espaços-tempos históricos, cujas transformações correspondem às relações que se estabeleceram por razões sociais, religiosas, culturais e político-econômicas, ao longo do tempo. A questão central do estudo encontrou-se na reflexão de como se exercem as relações entre a Igreja e a Universidade e quais as contribuições efetivas das Instituições, para realização do seu compromisso social.

A Universidade, sofreu os impactos estruturais das transformações sociais nos diferentes momentos da história, modificando seu caráter conceitual, organizacional e funcional. Também a Igreja precisou se adequar às exigências dos novos tempos. No mundo contemporâneo, a emergência da sociedade informacional, o estágio de desenvolvimento científico e tecnológico e a reestruturação do mundo produtivo, têm redefinido o escopo e as funções da Universidade, imputando-se novas formas de relações desta com a sociedade, bem como a Igreja que vem passando por ressignificação das formas eclesiais de evangelização.

Diante dessa realidade, é relevante a presença e o papel das Universidades, especialmente as públicas, frente aos desafios dos nossos tempos, que encontram nas demandas da sociedade, especialmente na equalização social e democratização, razões para implementar formas de acesso ao mundo acadêmico, colaborando na construção de novos horizontes e possibilidades de solução dos problemas sociais.

Enfim, ao refletir sobre a natureza e complexidade das relações entre Igreja e Universidade, descortina-se a vivência das realidades locais e as demandas sociais que se estabelecem, considerando que todos os processos que se desenrolam em diversos contextos, em uma dinâmica de influências estreitamente imbricadas, exigem de ambas as instituições, que estejam, cada vez mais, antenadas com os acontecimentos do mundo contemporâneo, visto que a existência e o papel que exercem, são permeados de vivências e acontecimentos, em espaço social e cultural, onde a convivência dos seres se dá.

Do movimento nascido no advento do Concílio Vaticano II, de grande pujança para a Igreja Católica, aqui no Brasil surgiram diversas iniciativas de 
formação de agentes para as pastorais, provenientes do anseio laical. Entre essas ações, foram surgindo as Escolas de Teologia para Leigos.

Na Diocese de llhéus, por meio do seu organismo formativo, o Instituto de Teologia de Ilhéus, foi criada em 1988 a Escola de Teologia para Leigos, possibilitando o acesso ao curso de Teologia, em nível propedêutico, aos agentes pastorais que não fazem parte da hierarquia eclesial.

A experiência da ETEL é uma maneira muito clara de acessibilidade e educação inclusiva, que tem por meta, a participação das pessoas, independente do seu nível cultural, social e religioso. Nessa perspectiva, é notória uma educação integradora, desburocratizada e acessível, visando um maior aproveitamento de conhecimento, de interatividade e de incidência direta na esfera social.

A parceria que a ETEL firmou com a UNEB, resultou no projeto com reconhecimento acadêmico, que visou dar formação teológica, em nível propedêutico, aos cristãos leigos da Diocese de Ilhéus que assumem serviços e ministérios na Igreja.

Isto foi possível pelo fato da UNEB ter um perfil, essencialmente democrático e inclusivo, acolhendo o projeto da ETEL, para promover o acesso ao conhecimento teológico de cristãos católicos leigos, em diversos núcleos de formação, em diferentes paróquias e municípios na região de abrangência da Diocese.

Atualmente, considerado de grande importância para as duas instituições, o curso da ETEL/UNEB, desenvolvido nos diversos Núcleos de Formação da Diocese, tem uma capilaridade muito abrangente em diversas comunidades, mobilizando pessoas para o aprendizado teológico, com grande repercussão na lgreja e na Universidade.

\section{Referências}

ALVES, Isabel Cristina Lima Dias; ASSIS, Otávio de Jesus. O DCHT Campus XXI (Ipiaú) e a Diocese de Ilhéus: Estabelecendo Parceria projeto de Extensão em Teologia. In: BORGES, Damião de Souza; SILVA, Sandra Célia Coelho da (Orgs.). Pensar e Construir: Experiências e Vivências. Curitiba: Brazil Publishing, 2020.

CELAM. Texto Conclusivo da V Conferência Geral do Episcopado Latino-Americano e do Caribe (13-31 de maio de 2007). Edições da CNBB, Paulinas e Paulus, 2007. 
CNBB. Cristãos Leigos e Leigas na Igreja e na Sociedade: Sal da Terra e Luz do Mundo (Mt 5, 13-14). Brasília: Edições CNBB, 2016. Documentos da CNBB, 105.

DAP. Documento de Aparecida. Texto Conclusivo da V Conferência Geral do Episcopado Latino-Americano e do Caribe. São Paulo: Paulinas, 2007.

DIÁRIO OFICIAL DO ESTADO DA BAHIA- DO, 20 de novembro de 2018, Ano CIII, n. 22.543. Disponível em: http://dovirtual.ba.gov.br/egba/reader2/. Acesso em: 11 abr./ 2020.

DSI. Compêndio da Doutrina Social da Igreja, n. 527. Disponível em: http://www.vatican.va/roman curia/pontifical councils/justpeace/documents/rc pc ju stpeace doc 20060526 compendio-dott-soc po.html. Acesso em: 11 nov./ 2020.

JOÃO PAULO II. Papa. Constituição Apostólica Ex Corde Ecclesiae, 15 de Agosto de 1990, n. 1. Disponível em: http://www.vatican.va/content/john-paulii/pt/apost constitutions/documents/hf jp-ii apc 15081990 ex-corde-ecclesiae.html. Acesso em: 11 jan./ 2021.

LAGHI, Pio Card.; PIRONIO, Eduardo Card; POUPARD, Paul Card. Presença da Igreja na Universidade e na cultura universitária. Disponível em: http://www.vatican.va/roman curia/pontifical councils/cultr/documents/rc pc cultr d oc 22051994 presence po.html.

Acesso em: 12 nov./ 2020.

MIDLEJ, Moema Maria Badaró Cartibani. Universidade e Região: Territorialidade da Universidade Estadual de Santa Cruz - UESC. 2004. Tese (Doutorado em Educação) - Faculdade de Educação, Universidade Federal da Bahia, Salvador, 2004. Disponível em: https://repositorio.ufba.br/ri/bitstream/ri/10615/1/Midlej\%20M.pdf. Acesso em: 11 jan./ 2021.

PAIVA, Jane; MACHADO, Maria Margarida; IRELAND, Timothy (ORGS.). Educação de Jovens e Adultos: uma memória contemporânea 1996 - 2004. Brasília: Ministério da Educação: UNESCO, 2005. Disponível em: http://pronacampo.mec.gov.br/images/pdf/bib volume1 eja uma memoria contemp oranea 1996 2004.pdf. Acesso: 16 nov./ 2020.

PONTIFÍCIO CONSELHO JUSTIÇA E PAZ. Compêndio da Doutrina Social da Igreja. São Paulo: Paulinas, 2005.

SEVERINO, Antônio Joaquim. A busca do sentido da formação humana: tarefa da Filosofia da Educação. In: Educação e Pesquisa. São Paulo, v.32, n.3, p. 619-634, set./dez. 2006 
Publicado em: 31 de dezembro de 2020 